\title{
A exclusão do outro na história do mesmo: uma tentativa nova de classificar o velho fundamentalismo religioso
}

\author{
The exclusion of the other in the history of the same: a new \\ attempt to classify the old religious fundamentalism
}

Breno Martins Campos ${ }^{1}$

\section{Resumo}

Como resultado de pesquisa conceitual, este artigo objetiva, antes de tudo, tratar de uma questão pertinente e insistente: como classificar o fundamentalismo religioso. Segundo o recorte bibliográfico adotado, considerase que toda tentativa de definir fundamentalismo deve se assumir incompleta. O substantivo fundamentalismo e o adjetivo dele derivados servem para nomear muitas coisas. Ainda assim, importa o nome, ou seja, não é qualquer coisa que pode ser chamada de fundamentalismo, pelo menos, não em sentido rigoroso. Com deslocamentos advindos da literatura e da filosofia ao campo dos estudos da religião, propõe-se definir fundamentalismo como a exclusão do outro na história do mesmo. Definição que permite pensar no fundamentalismo como um movimento antigo e presente desde sempre na história das religiões, especialmente nas monoteístas; e também como uma modelagem própria dada a ele por certos protestantes estadunidenses na passagem do século XIX para o XX. Por fim, a presença do fundamentalismo na política brasileira contemporânea é tomada como estudo de caso da manifestação de um velho habitante do mundo numa de suas novas formas de representação - com seus missionários e apóstolos a colocar em xeque a democracia e as conquistas democráticas.

Palavras-chave: Fundamentalismo religioso; Politica; Democracia; Brasil.

\begin{abstract}
Based on conceptual research, this article aims, first and foremost, to address a pertinent and insistent question: how to classify religious fundamentalism? According to the bibliographical sources adopted, it is considered that any attempt to define fundamentalism must be incomplete. The noun

\footnotetext{
${ }^{1}$ Doutor em Ciências Sociais pela Pontifícia Universidade Católica de São Paulo (PUC-SP). Docente permanente do Programa de Pós-Graduação Stricto Sensu em Ciências da Religião e professor da Faculdade de Ciências Sociais da Pontifícia Universidade Católica de Campinas (PUC-Campinas).
} 
Religare, ISSN: 19826605, v.15, n.2, dezembro de 2018, p.354-381.

fundamentalism and the adjective derived from it serve to name many things. Still, it matters the name, that is, it is not anything that can be called fundamentalism, at least not in the strict sense. With displacements arising from literature and philosophy to the field of studies of religion, we propose to define fundamentalism as the exclusion of the other in the history of the same. This definition allows us to think of fundamentalism as an ancient movement that has always been present in the history of religions, especially monotheists; and also as a specific conceptual modeling given to fundamentalism by certain American Protestants in the passage from the nineteenth to the twentieth century. Finally, the presence of fundamentalism in contemporary Brazilian politics is taken as a case study of the manifestation of an old inhabitant of the world in one of its new forms of representation - with his missionaries and apostles to challenge democracy and democratic achievements.

Keywords: Religious fundamentalism; Politics; Democracy. Brazil.

\section{Introdução}

Este artigo reflete acerca de classificações possíveis que consigam enquadrar (em mais de um sentido) o fundamentalismo religioso. Para exemplificar a incompletude própria da tarefa que se apresenta - cujo resultado, por definição, não deve agradar a todos -, proponho um debate introdutório, baseado em três autores brasileiros, cujas obras selecionadas percorrem um pouco mais do que os últimos 20 anos quanto à relação entre o nome fundamentalismo religioso e $a(s)$ coisa(s) que ele representa.

Seguindo a cronologia das publicações, destaco do primeiro autor selecionado, Ivo Pedro Oro (1996, p. 23), a seguinte opinião:

A necessidade de um conceito claro de fundamentalismo é urgente. Como se constata, nos últimos anos o termo fundamentalismo vem sendo prodigamente empregado em situações variadíssimas, tanto no campo religioso como no político. Fundamentalismo aparece, às vezes, como sinônimo de conservadorismo, sectarismo e fanatismo; como movimento ou corrente amarrados a modelos culturais religiosos do passado, fechados aos valores do mundo moderno e até mesmo às ciências. Tanto se fala em fundamentalismo que esse termo já está inflacionado. Em geral, carrega uma carga negativa e uma conotação pejorativa. Fundamentalista seria o fanático, o sectário, o intolerante, o conservador, o autoritário, o 
Religare, ISSN: 19826605, v.15, n.2, dezembro de 2018, p.354-381.

totalitário... e sempre são os "outros". Por causa disso, até os clássicos representantes desse movimento no protestantismo de hoje preferem o título de evangélico-conservador ao de fundamentalista.

Se nos tempos da pesquisa de $\mathrm{Oro}^{2}$ a tarefa de definir fundamentalismo era urgente, os nossos dias - especialmente se considerarmos que são tempos pós11 de setembro - elevaram a mesma exigência ao caráter de urgência urgentíssima. Reivindicação que pode tirar o sono de uns, isto é, daqueles que defendem o uso do nome associado a uma coisa somente, e levar outros, que admitem a legitimidade advinda do uso social do mesmo nome para várias coisas, à resignação de considerar que o indefinível (no singular) definido está (no plural). Como desdobramento dessa questão de fundo, o excerto citado de Oro é também capaz de demonstrar certas ambiguidades em torno do fundamentalismo, justamente por ser uma palavra que em pouco tempo ${ }^{3}$ experimentou significativa ampliação de seu campo semântico, tanto porque passou a dar nome a várias coisas dentro do campo religioso, seu locus originário, como porque outros campos, além do religioso, passaram a utilizar o substantivo fundamentalismo e os adjetivos derivados dele para nomear suas próprias coisas. ${ }^{4}$ No transcurso de um curto período, até quem havia se batizado positivamente de fundamentalista prefere não ser chamado desse modo, ainda mais hoje. Os protestantes fundamentalistas de outrora preferem ser conhecidos por outro nome agora. E o fundamentalismo continua a ser o lugar simbólico do outro: nós não somos fundamentalistas, eles é que o são.

Neste artigo, não está proposta uma definição de fundamentalismo religioso, a mais rigorosa possível, e que, portanto, seja aplicável somente ao

\footnotetext{
${ }^{2}$ A dissertação de mestrado $O$ outro é o demônio, que deu origem ao livro com o mesmo título, foi defendida por Oro em 1995 na Universidade Federal de Juiz de Fora. Há mais de 20 anos, portanto.

${ }^{3}$ Quanto a isso, Anthony Giddens (2000, p. 58) oferece um dado interessante: "Até o final da década de 1950, [...] não havia entrada para a palavra 'fundamentalism' no grande dicionário Oxford English. Ela só se tornou de uso comum a partir da década de 1960".

${ }^{4}$ Mantenho, neste artigo, o destaque que Oro dá ao fundamentalismo no campo político e, além disso, procuro discutir o encontro e as imbricações do fundamentalismo religioso com o político na arena pública.
} 
Religare, ISSN: 19826605, v.15, n.2, dezembro de 2018, p.354-381.

movimento originário ocorrido no seio do protestantismo estadunidense, numa época determinada (décadas finais do século XIX e iniciais do XX). Ainda assim, para não deixar minhas ideias sem nenhum parâmetro de aferição conceitual, recupero uma definição de fundamentalismo proposta por Antônio Flávio Pierucci (p. 152, 1992), o segundo dos três autores que elenquei:

Fundamentalismo [...] é o nome auto-aplicado de uma vertente do movimento protestante conservador, antiliberal, que se formou nos Estados Unidos a partir de 1870, nas principais denominações protestantes norte-americanas [...]. Seu objetivo básico era defender o princípio da inspiração divina plena da Bíblia, portanto sua inerrância, a autoridade absoluta da letra da Bíblia na vida do cristão. O adversário interno ao campo protestante contra o qual ele se constituiu foram os partidários da teologia liberal e dos métodos da crítica histórica e literária para interpretação da Sagrada Escritura cujo ensino passava a se propagar pelos seminários teológicos e escolas em geral, denominacionais e públicas. $\mathrm{O}$ adversário externo número um era a mentalidade científica moderna, representada emblematicamente pelo darwinismo.

Mais importante do que o didatismo dessa definição talvez seja a informação de que ela faz parte de um grande arrazoado de Pierucci no artigo "Fundamentalismo e integrismo: os nomes e a coisa", publicado em 1992, em que o sociólogo cumpre o importante papel de discutir o caso do fundamentalismo à luz da dificuldade de uma mesma palavra - ou expressão, no caso de fundamentalismo religioso - dar nome às multifacetadas expressões fundamentalistas na complexidade do real. Mais tarde, no ano de 1999, o mesmo texto foi publicado como capítulo final do livro Ciladas da diferença, em cuja apresentação Pierucci (1999, p. 7) faz duas perguntas decisivas: "Somos todos iguais ou somos todos diferentes? Queremos ser iguais ou queremos ser diferentes?". A tomada de decisão é uma exigência, pois o final do século XX arrastou-nos da certeza de que somos iguais para a consciência de que somos diferentes de fato e de direito. Eis que o fundamentalismo estava a passar de 
Religare, ISSN: 19826605, v.15, n.2, dezembro de 2018, p.354-381.

simples significante a despertar amor e ódio para a condição de objeto de investigação acadêmica. ${ }^{5}$

Mais recentemente, em 2017, Osvaldo Luiz Ribeiro, o terceiro dos autores escolhidos para esta introdução, publicou "Seis 'teses' sobre o fundamentalismo" (título de seu capítulo no livro Rostos do fundamentalismo) na condição de "provocações iniciais" (subtítulo do capítulo). O fundamentum históricometodológico de suas provocações pode ser esboçado do seguinte modo: o fundamentalismo é uma atitude religiosa dentro das religiões. Se dissermos que o fundamentalismo tem pai ou mãe, eles só podem ser a própria matriz religiosa (qualquer uma), em fase de catarse e agonia, da qual emerge esse fundamentalismo. Ribeiro (2017, p. 144-149) sustenta a "necessidade de revisão da narrativa padronizada sobre as origens históricas do 'fundamentalismo"' (Tese 1) e questiona "a relação [de filiação] entre 'fundamentalismo' e modernidade" (Tese 2). Das duas primeiras teses, o autor desdobra as outras quatro, nos campos da política, psicologia, epistemologia e intolerância - não exploradas neste artigo, com exceção daquilo que ele diz das relações entre religião (fundamentalismo) e política. ${ }^{6}$

\footnotetext{
${ }^{5}$ No contexto posterior à Revolução do Irã em 1979, informa-nos ainda Pierucci (p. 145, 1992), nenhuma palavra do universo islâmico capaz de dar nome àquele acontecimento (a coisa) era suficientemente conhecida no Ocidente: "O jeito foi recorrer às pressas ao baú de ismos das igrejas ocidentais". Foi assim que o substantivo fundamentalismo e o adjetivo fundamentalista, originalmente associados ao protestantismo dentro do campo religioso havia cerca de um século, migraram para setores do universo islâmico. No caso do 11 de setembro, portanto, já havia precedentes a explicar a associação do islamismo com o fundamentalismo. Hoje, a associação de fundamentalismo com fanatismo e intolerância é espontaneamente dirigida mais aos religiosos islâmicos do que aos cristãos protestantes propriamente.

${ }^{6}$ Ribeiro (2017, p. 145) considera monofocais as obras - inclusive a de Oro, dentre outras citadas por ele - que relacionam o fundamentalismo com a coletânea The Fundamentals e todo seu contexto: "É provável que isso se explique pela questão propriamente terminológica, já que o termo 'fundamentalismo' se pretende originar daquele movimento estadunidense [...], mas também pelo interesse imediato de certos autores com o universo propriamente evangélicoprotestante". Ele sugere que seja adotada outra perspectiva de abordagem histórica quanto às origens dos fundamentalismos (no plural) dispersos em nossos dias - e mesmo no passado -, pois "a homonímia entre o termo 'fundamentalismo' e o movimento The Fundamentals não deveria ser suficiente para estabelecer um como 'origem' do outro. Sequer por analogia" (RIBEIRO, 2017, p. 145). No desenvolvimento deste artigo, e no diálogo com os autores utilizados como referência, ficou evidente para mim como é difícil tratar do fundamentalismo religioso de outra maneira que não a monofocal. Por conseguinte, não vejo necessidade de anunciar todas as passagens deste artigo que se afastam das proposições de Ribeiro, cabendo ao leitor o juízo quanto aos
} 
Religare, ISSN: 19826605, v.15, n.2, dezembro de 2018, p.354-381.

O que há de mais provocador nas teses de Ribeiro (2017, p. 147) deve ser apresentado por ele mesmo:

Não é a modernidade que produz o fundamentalismo. O "fundamentalismo" já está presente quando a modernidade emerge das profundezas dos ciclos históricos. $\mathrm{O}$ fundamentalismo recebe seu nome no calor reacionário, na frente de batalha contra a emancipação crítica da cultura: mas o ser que recebe esse nome é antigo morador do mundo - é mesmo em sua casa que a modernidade entra, e é aí muito mal vinda...

Esse antigo morador do mundo, batizado ou apelidado de fundamentalismo há pouco mais de 100 anos, caracteriza-se, sobretudo, por uma luta histórica de poder dizer o que é a verdade - e que ela está, obviamente, em sua posse. Assim, fica difícil distinguir, por exemplo, monoteísmos de fundamentalismos (mesmo que com outros nomes). De acordo com a ideia central do ensaio de Ribeiro (2017, p. 142), "os fundamentalismos não 'nascem' na e da modernidade. Aí, surge apenas o nome".7 Para um contraponto à radicalidade das teses de Ribeiro, recorro a Umberto Eco: embora ele reconheça a coexistência contemporânea de várias formas de fundamentalismos, reconhece também que historicamente o fundamentalismo está mesmo ligado à interpretação de um livro sagrado. Assim, em sua forma ocidental moderna, o fundamentalismo nasceu no protestantismo estadunidense do século XIX, segundo o esforço de interpretar literalmente as palavras das Escrituras Sagradas, rejeitando leituras mais alegóricas do texto bíblico e também todo saber científico contrário à veracidade da Bíblia, notadamente o darwinismo - tudo muito parecido com a definição de Pierucci, não sem motivos. E arremata o escritor italiano:

riscos existentes tanto no reducionismo quanto no alargamento do sentido da palavra fundamentalismo e da expressão fundamentalismo religioso.

${ }^{7}$ Embora Ribeiro faça um esforço reconhecível para extrapolar o fundamento de suas teses a todas as religiões, seus argumentos e exemplos estão relacionados quase que exclusivamente aos monoteísmos. 
Religare, ISSN: 19826605, v.15, n.2, dezembro de 2018, p.354-381.

Essa forma de "literalismo" fundamentalista é antiga. Os Pais da Igreja já conheciam os debates entre os partidários da letra e os partidários de uma hermenêutica mais leve, como Santo Agostinho. Mas, na modernidade, o fundamentalismo estreito só podia virar um fenômeno protestante, porque, para ser fundamentalista, é preciso acreditar que o fundamento da verdade reside na interpretação da Bíblia (ECO, 2000, p. 1516). ${ }^{8}$

Para dar continuidade à reflexão acerca de um esquema possível de classificação que consiga enquadrar o fundamentalismo religioso, faço coro com as provocações de Ribeiro, com a licença dos rigoristas, a fim de poder tratar de fundamentalismo religioso de modo mais solto, deixando ao leitor a tarefa de avaliar se minhas ideias valem somente para o fundamentalismo protestante originário e seus desdobramentos mais óbvios - ou se elas podem ser estendidas a mais coisas chamadas pelo mesmo nome (fundamentalismo religioso). Ao tratar de classificações possíveis para o fundamentalismo, procuro distanciar-me daquela categoria de monofocalidade atribuída por Ribeiro a todo tipo de sustentação teórica que procura relacionar a gênese do fundamentalismo a seus marcos principais, com destaque óbvio para a coletânea The Fundamentals: a Testimony to the Truth (1910-1915). ${ }^{9}$ Pretendo aproximar-me do fundamentalismo - na condição dupla de fenômeno religioso com consequências sociais claras e, por extensão, de objeto de investigação acadêmica - segundo a lógica interna da exclusão do outro na história do mesmo, bem como perscrutar os deslocamentos provenientes da intrusão do

\footnotetext{
${ }^{8}$ Escolhi Umberto Eco como contraponto, pois o próprio Ribeiro, na última seção de seu texto, batizada de "Reflexões a título de síntese provisória", cita o livro O nome da rosa, do célebre autor italiano, à guisa de demonstrar as relações das invasões árabes na Europa com a introdução de Aristóteles nos mosteiros cristãos. Além de Eco, para afirmar mais um contraste às teses de Ribeiro, posso recorrer também a Anthony Giddens (2000, p. 57-58), inclusive, na mesma seção do texto já citado (para não acrescentar outra novidade a esta introdução): "Poderíamos pensar que o fundamentalismo sempre existiu. Isso não é verdade - ele surgiu em resposta às influências globalizantes que vemos por todos os lados à nossa volta. O próprio termo data da virada do século, quando foi usado para designar as crenças de certas seitas protestantes nos EUA, particularmente aquelas que rejeitavam Darwin". Pelo menos quanto ao tempo de nascimento do nome fundamentalismo, Giddens e Ribeiro parecem concordar.

${ }^{9}$ Cf. THE FUNDAMENTALS: a Testimony to the Truth, v. I-XII. Chicago: Testimony Publishing Company, [1910-1915]. Disponível em: http://archive.org/stream/MN40295ucmf_2\#page/n5/mode/2up. Acesso em: 9 ago. 2018.
} 
Religare, ISSN: 19826605, v.15, n.2, dezembro de 2018, p.354-381.

outro na história do mesmo, a fim de trazer à luz uma classificação nova para um velho dilema humano. Para novas direções são necessários novos caminhos. Portanto, valho-me, incialmente, de um diálogo com a literatura e a filosofia para além dos discursos das ciências da religião e da teologia, mais óbvios quanto ao caso - para alargar para fora das fronteiras do campo religioso o debate sobre o fundamentalismo.

\section{O fundamentalismo pode ou não ser tudo o que se diz dele - e até mais do que isso}

No ensaio "O idioma analítico de John Wilkins", Jorge Luis Borges (1999, p. 94) chega à notória conclusão de que "não há classificação do universo que não seja arbitrária e conjetural". ${ }^{10}$ Corolário: classificar não é um ato que possa ser considerado tarefa própria dos seres humanos, nem mesmo apropriada a eles, embora seja o tempo todo apropriada por eles (ou melhor, por nós). Argumento que se fortalece, no texto de Borges, com a hipótese de que talvez não exista nada parecido com a ideia a que está associada a palavra universo. De um lado, mesmo que houvesse um universo pleno de sentido, faltariam palavras, definições, etimologias, enfim, "as sinonímias do secreto dicionário de Deus" (BORGES, 1999, p. 95); e, de outro, "a impossibilidade de penetrar o esquema divino do universo não pode, contudo, dissuadir-nos de planejar esquemas humanos, mesmo sabendo que eles são provisórios" (BORGES, 1999, p. 95). ${ }^{11}$

\footnotetext{
10 No referido ensaio, publicado no livro Outras inquisições (de 1952), Borges "traça uma discussão sobre a arbitrariedade da linguagem por meio da proposta de John Wilkins de estabelecer uma língua universal a partir de noções comuns a toda a humanidade. Dessa forma, a língua estaria ligada à natureza das coisas e cada palavra se definiria a si mesma" (FUX; GOMES, p. 228, 2013).

${ }^{11}$ De acordo com o segundo relato da criação no livro de Gênesis $(2,19-20)$, o convite para nomear, no fundo, vem do próprio Deus: "Iahweh Deus modelou então, do solo, todas as feras selvagens e todas as aves do céu e as conduziu ao homem para ver como ele as chamaria: cada qual devia levar o nome que o homem lhe desse. $\mathrm{O}$ homem deu nomes a todos os animais, às aves do céu e a todas as feras selvagens" (tradução de A Bíblia de Jerusalém, nova edição, revista).
} 
Religare, ISSN: 19826605, v.15, n.2, dezembro de 2018, p.354-381.

As considerações que explicitam as ambiguidades, redundâncias e deficiências próprias do empreendimento de John Wilkins só aparecem no ensaio depois de Borges haver mencionado uma informação, creditada ao doutor Franz Kuhn, da existência de um sistema de classificação dos animais proposto por certa enciclopédia chinesa chamada de Empório Celestial de Conhecimentos Benévolos.

Em suas remotas páginas consta que os animais se dividem em (a) pertencentes ao Imperador, (b) embalsamados, (c) amestrados, (d) leitões, (e) sereias, (f) fabulosos, (g) cães soltos, (h) incluídos nesta classificação, (i) que se agitam como loucos, (j) inumeráveis, $(\mathrm{k})$ desenhados com um finíssimo pincel de pelo de camelo, (l) etcétera, $(\mathrm{m})$ que acabam de quebrar o vaso, (n) que de longe parecem moscas (BORGES, 1999, p. 94).

Trata-se de uma classificação curiosa, para dizer o mínimo, que guarda também suas próprias ambiguidades, redundâncias e deficiências. Não por coincidência, longe disso, Michel Foucault publicou, em 1966, o livro As palavras $e$ as coisas, dentre outros objetivos, para "pensar a classificação a partir da inclusão da diferença" (FUX; GOMES, p. 228, 2003). Logo na primeira frase do prefácio, o filósofo francês admite que seu livro nasceu de um texto de Borges. Justamente ao ler a respeito da divisão dos animais proposta pela enciclopédia chinesa, Foucault (1995, p. 5) conta que foi apanhado por um riso que fez perturbar todas as familiaridades do pensamento (o dele, o nosso, o de todos), "abalando todas as superfícies ordenadas e todos os planos que tornam sensata para nós a profusão dos seres, fazendo vacilar e inquietando, por muito tempo, nossa prática milenar do Mesmo e do Outro". O texto do Empório Celestial de Conhecimentos Benévolos é mesmo de fazer rir a todos, "não sem um mal-estar evidente e difícil de vencer" (FOUCAULT, 1995, p. 7).

Assumindo como verdadeiro que todo esquema humano de classificação ou organização de elementos distintos é provisório e arbitrário, no caso dos animais da enciclopédia chinesa, há pelo menos uma ordem garantida pelo abecedário (espécie de fio condutor), que se apresenta também como a garantia 
Religare, ISSN: 19826605, v.15, n.2, dezembro de 2018, p.354-381.

de que grupos diferentes de indivíduos possam ser comparados entre si. Além disso, por óbvio, cada organização estabelecida é sempre uma dentre muitas possibilidades de classificação ou divisão. É difícil às tentativas humanas de classificação aceitar que uma ordem diferente da estabelecida (ou daquela que se pretende manter) possa ser outra ordem e não necessariamente desordem ou desorganização. As ambiguidades e deficiências decorrentes de cada taxonomia podem ser a própria lógica da ordem num outro sistema ou universo de sentido e classificação.

Os códigos fundamentais de uma cultura - aqueles que regem sua linguagem, seus esquemas perceptivos, suas trocas, suas técnicas, seus valores, a hierarquia de suas práticas - fixam, logo de entrada, para cada homem, as ordens empíricas com as quais terá de lidar e nas quais se há de encontrar (FOUCAULT, 1999, p. 10).

A inclusão do outro na história do mesmo - noutros termos, a inclusão do exótico na história da organização familiar das coisas - sempre faz abalar os códigos fundamentais de uma cultura. O mal-estar vivido pessoalmente por Foucault, como experiência que pode ser estendida a todo ser humano, não é de outra ordem, senão a de estar diante de um sistema de classificação que inclui o outro. $\mathrm{O}$ encontro dialógico deste artigo com as ideias de Foucault traz à luz pelo menos duas consequências dos deslocamentos que o outro promove no mesmo - e não vai muito mais longe do que isso, por assumir direções outras. A primeira indica que uma espécie de coerência total (ou verdade absoluta) a autorizar a intransigência com o outro apresenta-se muito mais como impossibilidade do que como condição necessária a cosmovisões de quaisquer naturezas - impossibilidade talvez seja um exagero em face da realidade, marcada por discursos de ódio e por fanatismos de todas as espécies. A segunda, por sua vez, reconhece a plausibilidade de que os extremos podem estar mais próximos do que todos gostariam (tanto os iguais como os diferentes entre si), e que o encontro de polos opostos - por força ou atração dos desejos, especialmente daqueles menos confessáveis - insiste em se manifestar ou se 
Religare, ISSN: 19826605, v.15, n.2, dezembro de 2018, p.354-381.

revelar empiricamente. O campo religioso, representado pela imensa maioria das instituições, terá dificuldade de assimilar tanto a primeira consequência como a segunda. De modo particular, são proposições mentais com desdobramentos empíricos que fazem vacilar as estruturas do fundamentalismo religioso.

Além disso, é muito difícil - talvez impossível mesmo - a um fundamentalista reconhecer que aceder ao fundamentalismo é dar lugar à tentação primordial de ser como Deus. Pode um fundamentalista querer ou assumir o que deseja? É bem difícil, uma vez que a ele não é suficiente atender ao convite divino para dar nomes, consciente de que tudo não passa de provisoriedade, antes, o desejo inconfessável de um fundamentalista, aquilo que o leva à atitude fundamentalista, é conhecer o bem e o mal. A voz primordial da tentação, na atuação da serpente, não foi outra senão a de oferecer ao ser humano a posse da verdade: "Mas Deus sabe que, no dia em que dele comerdes [isto é, do fruto da árvore que está no meio do jardim], vossos olhos se abrirão e vós sereis como deuses, versados no bem e no mal" (Gênesis 3,5 - tradução de A Bíblia de Jerusalém, nova edição, revista).

Cada qual a seu modo, Borges e Foucault demonstram que classificar é preciso, por ser uma necessidade humana (até mesmo uma de nossas obsessões), mas sempre impreciso, por ser tarefa própria ao divino. Eles também observam que classificar é cometer equívocos, ou melhor, é ser parcial, pois um modelo de classificação exclui tantos outros - legítimos e competentes, eles mesmos. Situação que não é diferente no campo religioso, ou seja, toda classificação é temerária, ainda assim, não há razão para não nos arriscarmos. O limite insuperável a todo resultado de pesquisa é que nenhum rótulo simplificador apreende a realidade em sua complexidade. Por isso mesmo, importa assumir a parcialidade das classificações, pois nunca haverá palavras que nasçam espontaneamente da natureza das coisas.

Por analogia com aquilo que o Empório Celestial de Conhecimentos Benévolos fez em relação a animais, aplicado aqui a classificações possíveis do 
Religare, ISSN: 19826605, v.15, n.2, dezembro de 2018, p.354-381.

fundamentalismo religioso, este artigo pretende ocupar uma posição que venha depois do etcétera. Por impróprio que pareça a qualquer outro ordenamento, na lista proposta pela enciclopédia chinesa, o etcétera está identificado pela letra "(l)" e, surpreendentemente, vem antes de mais dois itens: o "(m)", dos animais que acabam de quebrar o vaso, e o "(n)", daqueles que de longe parecem moscas. Segundo o padrão normativo para a composição de listas, resta claro que um etcétera intermediário - ou seja, não posicionado no fim da lista dos elementos que o antecedem - revela uma incongruência; mas não na enciclopédia chinesa, nem aqui. Na prática, fundamentalismo é tudo o que se diz dele e, empírica ou tacitamente, também outras coisas - e, na sequência, outras coisas mais. Vamos a elas.

\section{O fundamentalismo é mais do mesmo - e nada do outro}

Ainda que o fundamentalismo tenha existido como atitude nas religiões em todos os tempos, como propõem as teses de Ribeiro, não é de se desprezar que na modernidade ele tenha se apropriado de um discurso próprio inclusive, para dar respostas às especificidades da modernidade. Considero diferente a resposta fundamentalista moderna à modernidade (com o nome de fundamentalismo) em comparação com as respostas fundamentalistas da tradição em face dos desafios à religião em quaisquer épocas. De todo modo, faço questão de registrar aqui três flagras, segundo Ribeiro, de fundamentalismo (antes do nome) na tradição neotestamentária: (1) o Paulo de Gálatas ensina considerar anátema qualquer um - anjo ou ser humano - que ensina um evangelho diferente do dele; (2) a carta de Tito considera conveniente tapar a boca de quem ensina o que não deve ser ensinado (ou o que não é a verdade), e somente o autor da carta é quem conhece a Deus; (3) a epístola de Judas exorta seus destinatários a defender a fé e lutar por ela. "O que falta para que o quadro geral constituído por Gálatas, Tito e Judas possa ser considerado um exemplo de fundamentalismo? Sim, falta o nome" (RIBEIRO, 2017, p. 149). Em sentido 
Religare, ISSN: 19826605, v.15, n.2, dezembro de 2018, p.354-381.

estrito, não é tão simples dizer que se trata apenas de um novo nome para um velho ser que sempre habitou o mundo - antes, importa o nome.

Em livro publicado há pouco tempo, reunindo ensaios e artigos de divulgação (alguns dos anos 1990), Mario Vargas Llosa se põe a debater as metamorfoses da palavra cultura e seus múltiplos sentidos, e a pensar a contemporaneidade como civilização do espetáculo. ${ }^{12}$ Também o tema do fundamentalismo religioso foi trabalhado pelo autor dentro de uma reflexão mais ampla sobre secularização (no capítulo "O ópio do povo").

A secularização não substituiu os deuses por ideias, saberes $e$ convicções que desempenhassem suas funções. Deixou um vazio espiritual que os seres humanos preenchem como podem, às vezes com sucedâneos grotescos, com múltiplas formas de neurose, ou dando ouvidos ao chamado dessas seitas [Vargas Llosa está a tratar da Igreja da Unificação, do reverendo Moon] que, precisamente por seu caráter absorvente e exclusivista, de planejamento minucioso de todos os instantes da vida física e espiritual, proporcionam equilíbrio e ordem àqueles que se sentem confusos, solitários e aturdidos no mundo de hoje (VARGAS LLOSA, 2013, p. 178).

As opiniões do ensaísta peruano inserem no debate da secularização o fenômeno, ao mesmo tempo conceitual e social, batizado de a morte de Deus, no sentido daquilo que, segundo certa mentalidade iluminista, deveria ter criado uma sociedade laica e, por conseguinte, livre da violência, guerras e matanças de caráter fanático-religioso. Ainda segundo Vargas Llosa (2013, p. 17), a morte de Deus não significou o advento do paraíso na Terra, mas o do inferno: "o mundo, livre de Deus, foi sendo aos poucos dominado pelo diabo, pelo espírito do mal, pela crueldade e pela destruição". O diabo, no sentido etimológico daquele ou daquilo que desune, encontra no discurso e ethos fundamentalistas uma de suas manifestações, pois o fundamentalismo, ao reunir iguais, não cessa de desagregar pessoas dos vínculos sociais não religiosos ou dos pertencimentos religiosos pregressos. Além disso, ao criar fortes vínculos

\footnotetext{
${ }^{12}$ Como não poderia deixar de acontecer, Vargas Llosa assume a semelhança dos títulos de seu livro (A civilização do espetáculo) com o de Guy Debord (A sociedade do espetáculo), de 1967, ao mesmo tempo em que recusa como referência as categorias teóricas da obra do francês.
} 
Religare, ISSN: 19826605, v.15, n.2, dezembro de 2018, p.354-381.

identitários, acaba por tornar todo outro um adversário. O fundamentalismo, ao mesmo tempo, cria um mundo cindido e se alimenta dele.

Ser um dentre os deuses (ou ser como Deus), conhecedor do bem e do mal, talvez seja mesmo algo muito difícil de um fundamentalista assumir como seu. O que, na prática, é aceito sem muitos problemas, pois todo fundamentalista assume discernir as diferenças entre o bem e o mal, o certo e o errado, enfim, o que é a verdade - discernimento que pretende impingir a todo custo a toda e qualquer pessoa. Assim, o ser como Deus, no sentido de estar no lugar de Deus, é substituído pelo estar com Deus, ao lado dele, do lado certo, enfim, com a verdade.

Sentir-se escolhido ou eleito é outra das fortes seduções do fundamentalismo. Para o modus operandi fundamentalista, é imprescindível criar e manter a distinção entre nós e eles. Trago Pierucci novamente à cena, como especialista na sociologia da religião (ou da religião na sociologia) de Max Weber. Ao tratar daquilo que o sociólogo alemão chamou de religiosidade soteriológica congregacional, ${ }^{13}$ Pierucci chega a uma conclusão que também faz abalar algumas de nossas convicções, ao deslocar a religião do religare para o relegere. Se, para Émile Durkheim, "a religião atua como religação dinamogênica do indivíduo com a sociedade a que pertence" (PIERUCCI, p. 111, 2006), para Weber, "o indivíduo destituído de laços é a unidade simples que lhe interessa [à religião] coletar (re-legere), coisa que vai fazer interpelando-o diretamente na segunda pessoa do singular" (PIERUCCI, p. 123, 2006). É muito interessante a

\footnotetext{
${ }_{13}$ Para uma noção mais clara dos comentários de Pierucci à sociologia weberiana, julgo oportuno transcrever o trecho de Weber (1982, p. 377) que colocou o sociólogo brasileiro a pensar mais detidamente sobre o caso: "Sempre que as profecias de salvação criaram comunidades religiosas, a primeira força com a qual entraram em conflito foi o clã natural, que temeu a sua desvalorização pela profecia. Os que não podem ser hostis aos membros da casa, ao pai e à mãe, não podem ser discípulos de Jesus 'Não vim trazer a paz, mas a espada' (Mateus $\mathrm{X}$, 34), foi dito quanto a isto, e, devemos observar, exclusivamente em relação a isto. A maioria preponderante de todas as religiões regulamentou, é claro, os laços de piedade do mundo interior. Não obstante, quanto mais amplas e interiorizadas foram as metas da salvação, tanto mais ela aceitou sem críticas a suposição de que o fiel deve, em última análise, aproximar-se mais do salvador, do profeta, do sacerdote, do padre confessor, do irmão em fé, do que dos parentes naturais e da comunidade matrimonial".
} 
Religare, ISSN: 19826605, v.15, n.2, dezembro de 2018, p.354-381.

definição da religião como solvente, proposta por Pierucci (p. 122, 2006) em diálogo muito fecundo com Weber:

Eis uma forma de religião [universal de salvação individual, aberta a todos] especialmente diruptiva, efetivamente destrutiva. Diruptiva e predatória, extrativista. E de fato. Uma religião de salvação individual só se apruma num primeiro momento por via extrativa: extrai sistematicamente os membros das outras coletividades, das quais, antes de ouvir a "boa nova" que interpela à apostasia, eles se pensavam estrutural e inercialmente como parte e parcela. Mas não, religião de conversão não tem a menor consideração. Destaca partes e desata nós, despedaça relações sociais herdadas e desmembra coletividades já constituídas. Congregacionalista, "com-grega" indivíduos que ela própria "des(a)grega" de outras greis, por secessão ou abdução, indivíduos que ela recruta desenraizando, desterritorializando-os de seus assentamentos convencionais, desviando-os de suas rotas convencionais, desqualificando sistematicamente outros sistemas religiosos de crença e vida prática, criticando ou condenando sem pedir licença outras condutas de vida e pautas de comportamento, religiosas ou não, coletivas ou não, significativas ou não.

Não é diretamente de fundamentalismo religioso que Pierucci está a tratar, porém, por adaptações que faço mais ou menos livremente, suas proposições podem ser aplicadas também ao fundamentalismo (como modelo radicalizado de religião de salvação), que desagrega para congregar (mecanismo próprio de conversão religiosa), desqualifica qualquer pensamento e discurso que não sejam iguais ao seus, e critica qualquer outro ethos que não seja o seu. Com uma vantagem em relação ao modelo tradicional de congregação, o fundamentalismo tem a capacidade de criar uma comunidade metaeclesiástica, ou seja, formada por fiéis de muitas igrejas (em sentido sociológico), desde que façam a mesma declaração de fé e assumam a mesma ética.

Dentro de uma mesma religião, por exemplo, o movimento fundamentalista pode estar presente em todas as congregações (comunidades) sem precisar se tornar uma nova e singular instituição; para o bom funcionamento do fundamentalismo, a comunidade nem precisa se chamar 
Religare, ISSN: 19826605, v.15, n.2, dezembro de 2018, p.354-381.

fundamentalista, é até melhor que não se identifique desse modo (em face das múltiplas críticas da sociedade contemporânea a esse designativo) - vale lembrar que, até para os fundamentalistas, fundamentalista é sempre o outro. Assim, o fundamentalismo fica com o bônus do exercício da crítica profética autônoma quanto ao status quo da totalidade das comunidades de uma mesma religião (noutros termos, "os outros estão todos errados"); e sem o ônus da institucionalização sacerdotal, pois não é responsável direto por nenhuma das comunidades. O locus simbólico do fundamentalismo no campo religioso pode ser considerado o melhor de dois mundos. Ao criar uma metacomunidade com fiéis de várias igrejas dentro de uma mesma religião, ou ao atrair fieis de outras religiões para sua metacomunidade dentro de uma determinada religião, o fundamentalismo congrega; e, no mesmo movimento, desagrega, pois ao fiel fundamentalista só resta aderir ao discurso e prática do fundamentalismo, rompendo vínculos com os de fora da religião e também com os de dentro mas não fundamentalistas. $\mathrm{O}$ que não é a mesma coisa de considerar o fundamentalismo como um movimento sem divergências internas, ou que não existam confrontos entre fundamentalismos.

Moderno ou pré-moderno - ou, ainda, como prefere Ribeiro (2017, p. 146), "reação da cultura pré-moderna à cultura moderna" -, o fundamentalismo vem sendo francamente favorecido pelas ferramentas da modernidade na civilização do espetáculo, porque elas são capazes de criar redes sociais (não necessariamente presenciais) em torno de um pensamento único, de uma única verdade. Redes que se alimentam do discurso e lógica da confirmação de suas próprias ideias - espécie clara de um "mais do mesmo" levado às últimas consequências -, nas quais o outro não tem lugar. Eliminar, deletar, excluir, bloquear, banir, silenciar, dentre outros afins, são os verbos que denotam o lugar do outro dentro da mesmice fundamentalista a que as redes sociais e seus grupos de pertencimento estão sujeitos. Sem falar nos discursos de ódio e intolerância facilitados pela proteção que os grupos de iguais na internet oferecem aos aderentes. Trata-se, portanto, de uma mesmice capaz de 
Religare, ISSN: 19826605, v.15, n.2, dezembro de 2018, p.354-381.

proporcionar aquela ordem e equilíbrio, mencionados por Vargas Llosa, que faltam ao sujeito contemporâneo no seu cotidiano. Estar com a verdade e cercado por muitos que concordam com isso, convenhamos, é uma espécie de proteção em rede ou em cadeia. Quem corre perigo são os outros - de longe, todos parecem moscas.

\section{O fundamentalismo está aqui e ali}

É muito difícil que um fundamentalista ative a hermenêutica a considerar que o eu é um outro, e que "cada um dos outros é um eu também, sujeito como eu" (TODOROV, 1999, p. 3), assim, com a redução máxima da diferença ao dualismo "nós versus os outros", resta todo um mundo a conquistar. A causa fundamentalista é lutar para que a diferença seja negada ao outro, de fato e de direito. A um fundamentalista, está interditada a noção de perspectiva: "somente meu ponto de vista, segundo o qual todos estão lá e eu estou só aqui, pode realmente separá-los e distingui-los de mim" (TODOROV, 1999, p. 3).

No livro O futuro da fé, cujos capítulos discutem o que o futuro reserva para a religião em geral e para o cristianismo em particular, Harvey Cox (2015) trata também das comunidades fundamentalistas de proteção e da abençoada segurança oferecida por elas aos fiéis nativos e aos aderentes; e também assume compreender os fundamentalistas por ter sido um deles, ainda que por pouco tempo.

Tendo experimentado, antes, ao menos uma centelha do vigor que motiva os fundamentalistas cristãos, fico sempre fascinado por seus movimentos e ainda sinto certa empatia por eles. Não consigo deixar de admirar seu compromisso e sua força. Às vezes ainda me pego cantarolando os majestosos hinos que aprendi com eles. No entanto, também sei quanto esforço é preciso para ser fundamentalista. Pode ser cansativo. Você precisa lutar constantemente não só contra o ceticismo das pessoas à sua volta, mas também contra as dúvidas que surgem em você mesmo. Os fundamentalistas despertam em mim 
Religare, ISSN: 19826605, v.15, n.2, dezembro de 2018, p.354-381.

tristeza mais do que tudo. Seu pathos é desperdiçar tanta energia numa causa perdedora (COX, 2015, p. 202).

Segundo Cox, o fundamentalismo é beligerante ou não é fundamentalismo. Aliás, deve ser mesmo um esforço muito cansativo colocar em ato tanto ódio à dúvida do outro (num mecanismo que pode até ser inconsciente) e também ao outro (de forma manifesta), pois o que um fundamentalista odeia é seu próprio desejo de poder duvidar - como faz e assume o não fundamentalista. Cercar-se de iguais gera uma sensação de proteção, que provém da certeza absoluta compartilhada socialmente, da verdade em que todos acreditam ou afirmam acreditar. Que os fundamentalistas são, em regra, convertidos pregando a convertidos é bem verdade, mas não só: eles vão ao outro também, de forma mais ou menos violenta, mas sempre com violência.

Parece compreensível a todos nós, como afirma Cox, que a beligerância fundamentalista se manifeste no dispêndio de energia para manter o próprio grupo coeso (congregar), assim como para convencer o outro à sua volta a superar o ceticismo e a abraçar o ethos do fundamentalismo (desagregar para recongregar). Parece mesmo compreensível que os fundamentalistas se apresentem ao outro, por exemplo, por meio de publicação e distribuição de livros e folhetos, pela veiculação de programas na mídia, ou por encontros públicos com sermões, pregações, hinos etc. - o que, por si só, não deixa de ser um grande esforço. A intensidade da força exigida aumenta à medida que a beligerância fundamentalista sai à conquista de novos territórios (simbólicos ou concretos) e de novas pessoas. Em sua luta contra a possibilidade e legitimidade da diferença, o fundamentalismo ocupa também o espaço para fora das fronteiras do campo religioso. Enfim, fundamentalismo não é só o entoar de hinos majestosos em espaços cúlticos apropriados ao serviço religioso; não se trata somente de compromisso e força com causas religiosas.

$\mathrm{Na}$ arena pública contemporânea, em face da histórica conquista de liberdade às diferenças, depois de muitas e intermináveis lutas pela instauração 
Religare, ISSN: 19826605, v.15, n.2, dezembro de 2018, p.354-381.

da laicidade do Estado, o fundamentalismo procura a todo custo, de novo e sempre, ocupar o lugar de Deus (ou algo bem próximo disso). Parece insuportável a liberdade de poder viver sem Deus: é preciso nos livrarmos dela, diria o fundamentalista.

[O impasse mortífero do fundamentalismo] equivale a fazer-se porta-voz do Pai, seu tenente, seu substituto, até colocar-se em posição de exigir uma vingança absoluta contra todos os que deixaram cometer esse crime [a morte do Pai], tornando-se, assim, passíveis de um castigo impiedoso, até o último deles. Todos os homens tornam-se então possíveis infiéis culpados, isto é, justiçáveis. Eis porque os restauradores fundamentalistas do Pai, especialistas em atentado cego, não gostam de nada mais que se fazer algozes dos outros homens, considerados todos culpados (DUFOUR, 2014, p. 16-17).

Para garantir uma comunidade de iguais (contra o resto), a conquista do outro nem sempre se dá pelo atentado terrorista - aliás, o que mais aparece sob a lógica e a luz do espetáculo no contemporâneo. As bombas fundamentalistas podem ganhar materialidade na forma de mísseis (em questões de Estado), mas também na de missionários a serviço de religiões (e de Estados). Etimologicamente, mísseis e missionários são parentes próximos e se referem a enviados. Por extrapolação dos limites pessoais do comentário de Cox, não me parece compreensível nem tolerável o lançamento de mísseis ou aviões de carreira, nem de bombas ou homens-bomba, contra o outro - em nome de uma verdade singular construída segundo os interesses da idolatria da mesmice.

Em sua terceira tese sobre o fundamentalismo, Ribeiro (2017, p. 149) argumenta que "o elemento político do fundamentalismo é importado da base política monoteísta" - e, assim, também não deve nada à modernidade. Para corroborar suas ideias, utiliza exemplos que vêm do monoteísmo judaico neotestamentário em face das políticas romanas, e do cristianismo do século IV em suas relações com o Império - e conclui:

A relação entre religião e poder, entre teologia e política, é indiscutivelmente anterior à modernidade, de sorte que o 
Religare, ISSN: 19826605, v.15, n.2, dezembro de 2018, p.354-381.

fundamentalismo, nominalmente moderno, é, todavia, essencialmente pré-moderno, e sua relação umbilical com a política é apenas a manutenção das relações entre monoteísmos e política que se iniciaram já nas origens dessa particular forma política de fé religiosa (RIBEIRO, 2017, p. 151).

Estamos diante de mais uma proposição de Ribeiro que se justifica como discussão epistemológica - não sem importância, acrescento -, mas que não atende de modo integral aos interesses deste artigo. Ao propor uma discussão quanto a novas formas de classificação para o fundamentalismo, não quero somente poder afirmar que ele sempre esteve por aí, em quaisquer tempos e espaços, com maior ou menor dose de dramaticidade. É preciso pensar que hoje - e somente hoje, para evitar anacronismos - os fundamentalismos religiosos colocam em questão a democracia e o direito às diferenças, não para criticar a democracia como está e radicalizar as conquistas democráticas, mas para propor um retorno ao passado idealizado. No Brasil contemporâneo, por exemplo, não lidamos com mísseis ou aviões transformados em bombas, nem com homens e mulheres que fazem de seus corpos bombas contra o outro, em contrapartida, cresce nossa preocupação com a chegada dos fundamentalistas religiosos à cena pública pelos caminhos da política. Fato particular que não é a mesma coisa de qualquer relação entre religião e poder, ou entre teologia e política, em qualquer época.

No mesmo livro - Rostos do fundamentalismo - em que Ribeiro propõe suas seis teses, Douglas Ferreira Barros apresenta e discute um caso particular que, para ele, refere-se à presença do fundamentalismo religioso no Brasil contemporâneo a colocar a nossa democracia em questão: ${ }^{14}$ a Proposta de Emenda à Constituição (PEC) 12/2015 do Deputado Federal Cabo Daciolo

\footnotetext{
${ }^{14}$ Segundo Barros (2017, p. 113-114), "pensar o fundamentalismo no contexto das democracias contemporâneas é desafio complexo. As diversas acepções que o termo comporta tornam suspeitas as tentativas de se reduzi-lo a um mesmo fenômeno sociopolítico descontextualizado, que abarca inúmeras ações, movidas por interesses e objetivos diferentes e lugares muito distintos". Com razão, são diferentes as ações fundamentalistas em contextos também diferentes, por exemplo, em face de um império na antiguidade ou dentro de uma democracia na modernidade. Além disso, não deixa de ser interessante que Barros, na passagem em que
} 
Religare, ISSN: 19826605, v.15, n.2, dezembro de 2018, p.354-381.

(primeiro subscritor) - para alterar a redação do parágrafo único do art. $1^{\mathrm{o}}$ da Constituição Federal, a fim de declarar que todo poder emana de Deus (em vez de emanar do povo, como reza o texto constitucional). ${ }^{15}$

Como se se tratasse em sua proposta de mera alteração semântica sem maiores consequências, Daciolo apresentou no início do ano legislativo de 2015 a PEC (Proposta de Emenda Constitucional) 12/2015, também chamada de PEC dos Apóstolos pelo deputado e por inúmeros representantes da bancada dos evangélicos. A nova redação ao artigo dizia que: "Todo o poder emana de Deus, que o exerce de forma direta e também por meio do povo e de seus representantes eleitos nos termos desta Constituição" (BARROS, 2017, p. 112). ${ }^{16}$

Segundo o dualismo que preside todo sistema de classificação fundamentalista do mundo, das coisas e das pessoas, troca-se o povo por Deus no texto da Constituição e fica restabelecida a verdade - simples assim e vida que segue. O porquê de a democracia estar em questão parece óbvio, mas o modo como Barros (2017, p. 124) relaciona fundamentalismo religioso com práticas antidemocráticas no Brasil contemporâneo, em diálogo crítico com a teologia política em Carl Schmitt, traz à luz explicações que não podem passar sem registro:

Um posicionamento teológico político é aquele que se espelha no ordenamento sócio-político avesso à multiplicidade, à diversidade, às divisões. $\mathrm{A}$ unidade entre soberano $\mathrm{e}$ subordinados supõe que a autoridade que ocupa a supremacia do poder esteja amparada na fidelidade inconteste por parte dos que lhe estão assujeitados. Dissidências são tidas como traição dos princípios ordenadores da unidade, desvios inaceitáveis.

precisa se valer de uma definição de fundamentalismo religioso, recorra justamente à de Oro (que é monofocal, segundo Ribeiro). É mesmo complexo esse fundamentalismo.

15 Para acesso a texto integral, cf. http://www.camara.gov.br/proposicoesWeb/prop_mostrarintegra?codteor=1313782\&filename=T ramitacao-PEC+12/2015. Acesso em: 8 set. 2018.

${ }^{16}$ Para o conteúdo todo da matéria utilizada e citada por Barros - intitulada "Deputado quer trocar povo por Deus na Constituição" -, cf. https://congressoemfoco.uol.com.br/especial/noticias/deputado-quer-trocar-povo-por-deus-naconstituicao/. Acesso em: 29 ago. 2018. 
Religare, ISSN: 19826605, v.15, n.2, dezembro de 2018, p.354-381.

A redação da PEC 12/2015 - ela mesma, um sintoma do Brasil contemporâneo -, impõe, mais uma vez, o desejo mais ardente do fundamentalista: que o representante eleito pelo povo seja também um representante eleito por Deus, ou seja, o próprio fundamentalista (ou alguém que lhe seja bem próximo) - típico desejo de legitimação de superioridade. Concordamos com Barros (2017, p. 113) na constatação de que estamos diante de "um novo tipo de atuação política do protestantismo brasileiro [mas não restrita a ele], identificada aos princípios religiosos fundamentalistas como suporte de seu posicionamento público e da ação nas instituições públicas em todo os níveis (municipal, estadual e federal)" - e, ainda, que a sustentação para tudo isso reside na premissa de que os princípios religiosos têm prevalência em relação aos republicanos (inclusive, na Constituição).

Se a PEC 12/2015 foi batizada pelos próprios proponentes de "PEC dos Apóstolos", não considero sem propósito lembrar que apóstolo, etimologicamente, é também enviado (origem grega) - e, por extensão, porta-voz e substituto (de Deus, no caso em questão) -, como mencionamos antes acerca de mísseis e missionários (origem latina). Aqui, importam os nomes.

\section{Considerações finais}

Ao debater que o fundamentalismo religioso coloca em questão a democracia, Barros (2017, p. 133), lança a si mesmo - e deixa também no ar uma questão: "a democracia, que supõe o constante embate e disputa entre grupos com interesses conflitantes, ao incorporar como legítima a influência sobre o poder por parte de grupos religiosos, termina por fomentar sua própria fragilidade?". Pelo respeito às diferenças, a democracia acomoda também modelagens mais fundamentalistas de religiões e religiosidades, portanto, é 
Religare, ISSN: 19826605, v.15, n.2, dezembro de 2018, p.354-381.

justo pensar que, pelo esgarçamento teórico e empírico de suas convicções, a democracia tem de lidar com certa fragilidade. ${ }^{17}$

O fundamentalismo, mesmo dentro da democracia, faz-se acompanhar do antipluralismo que "pressupõe a recusa da diferença" e "convida à supressão ou eliminação do outro que incorpora a diferença", cujos princípios e desdobramentos são antidemocráticos na forma da "hostilidade ostensiva em relação àqueles que adotam distintas orientações - religiosas, morais ou políticas" (BARROS, 2017, p. 129-130). Está posto um embate: quanto mais democracia, mais possibilidades para fundamentalismos religiosos; quanto mais fundamentalismos, menos democracia. Ou não.

Fortalecer a democracia inclui o diálogo com os fundamentalistas - com o quê nem todo mundo concorda, até porque, convenhamos, há diferenças entre fundamentalistas e fundamentalistas, alguns podem só cantar hinos majestosos, outros podem se transformar em bombas. A despeito das críticas que possa receber, sigo concordando com Louis Schweitzer (2001, p. 42):

Se vamos reagir, precisamos ter cuidado para não execrar as pessoas que não pensam como nós. [...] Com certeza, teremos de nos opor, mas sempre estendendo pacientemente as mãos para o diálogo, para que, em nosso pensamento e em nossa prática, não nos tornemos a imagem do outro refletida no espelho.

Dado o problema da fragilidade da democracia, minha resposta vai a uma direção diferente da proposta por Barros - por causa da coerência com o escopo deste artigo -, não sem antes concordar com ele acerca de mais dois

\footnotetext{
${ }_{17}$ Barros (2017, p. 125) considera que "nem todo fundamentalismo pressupõe a confrontação ou impõe ameaças à democracia. É possível que determinado grupo religioso seja fundamentalista, sem que esse princípio se coloque como legitimador de ações supremacistas em relação a quem não é fundamentalista, seja no caso de religiões seja em contextos sociais e políticos amplos". De minha parte, proponho que o fundamentalismo é supremacista, não necessariamente em sentido teológico político, ou não é fundamentalismo. Sempre há um desejo de superioridade investido no esquema fundamentalista. De todo modo, de seu pressuposto formal, Barros deduz um argumento que serve como exagero da realidade, na condição de método de investigação do real, o de que o fundamentalismo chegou à política no Brasil, a colocar nossa democracia em questão, por força e obra dos pentecostais e neopentecostais - e sua nova forma de agir politicamente.
} 
Religare, ISSN: 19826605, v.15, n.2, dezembro de 2018, p.354-381.

dados: o pluralismo de uma sociedade em geral - e da brasileira, em particular - é tão mais legítimo quanto possa garantir as diversidades (de cosmovisão, ética, política, religião etc.); além disso, numa democracia em geral - e na brasileira, em particular -, "a verdade que está na base de todas as certezas fundamentalistas [...] concorre com outras verdades - religiosas, não religiosas, antirreligiosas - para conquistar a opinião e os desejos dos cidadãos" (BARROS, 2017, p. 129).

Voltemos, então, a atenção ao caso narrado por Cox (2015): é claro que ele está a tratar do fundamentalismo protestante estadunidense do qual fez parte durante um breve tempo de sua vida, ainda assim, por ampliação de suas ideias a outros fundamentalismos religiosos, não dá para reconhecer em que base material se assenta a opinião dele de que a causa fundamentalista é perdedora. Ao contrário, está em crescimento, tanto no campo da violência simbólica como no terreno da violência em forma de terrorismo.

Como exercício, podemos pensar que o fundamentalismo ganha batalhas, mas nunca vencerá a guerra contra o outro por completo, por razões internas, próprias de seu modus operandi: ele precisa sempre de um adversário, de um inimigo. O fundamentalismo se alimenta da cizânia, constitui-se contra o outro, é um típico caso de identidade reacionária, ou seja, afirmada pela negação da identidade do outro. Se determinado fundamentalismo religioso trouxesse todo o mundo para sua verdade - o que parece impossível, haja vista a existência de confrontos sem solução iminente também entre fundamentalismo e fundamentalismo -, o momento seguinte ao da conquista do mundo seria também o da primeira cisão interna, criando e estabelecendo uma nova disputa em torno da verdade e da posse da verdade.

Fundamentalismo pode ser muita coisa - e até mais do isso -, como este meu artigo pretendeu esboçar e discutir. Em contrapartida, ao longo do texto, deixei latente - e, aqui, torno patente - que minha discussão é menos sobre os apóstolos fundamentalistas monoteístas lá do passado, bem antes de existir o nome fundamentalismo para chamar de seu, e mais sobre os fundamentalistas 
Religare, ISSN: 19826605, v.15, n.2, dezembro de 2018, p.354-381.

apóstolos do presente - e no Brasil. O terreno político é dos mais férteis para a atuação dessa forma de expressão religiosa, caracterizada pela rejeição ao diálogo e pela conquista proselitista de espaço e de adeptos. Concordo com o teor das seguintes palavras de Anthony Giddens (em entrevista a Christopher Pierson), embora a primeira frase seja desconcertante, embora na primeira frase ele opte por uma datação muito recente para o nome fundamentalismo:

Creio que o fundamentalismo é fenômeno recente. O termo só se tornou corrente na década de 1970. A meu ver, o fundamentalismo é a tradição travando uma luta feroz contra um mundo cosmopolita e reflexivo que está à procura de razões. É mais do que uma cisão entre as diferentes categorias de crente verdadeiro: é não-participação deliberada na "conversação cosmopolita com a humanidade" de que fala o filósofo Richard Rorty. A recusa ao diálogo - a insistência em afirmar que somente é possível uma visão do mundo e que já se possui essa visão - tem efeito nocivo num mundo que necessita cada vez mais desse diálogo. O fundamentalismo é um conceito que só tem sentido sobre o pano de fundo da modernidade recente - a generalização e a radicalização das instituições modernas.

Ele pode ser alimentado pelos mesmos sentimentos que originaram o fanatismo em épocas passadas, mas sua importância para nós é outra, e seu teor não é o mesmo. $\mathrm{O}$ fundamentalismo é a tradição que conscientemente se opõe à modernidade, mas que ao mesmo tempo assume feições modernas e não raro se utiliza de tecnologias modernas (GIDDENS; PIERSON, 2000, p. 97).

A busca de razões é insuportável para quem julga já haver encontrado a razão (assim, no singular). Não há reflexividade no fundamentalismo. Giddens alarga suas proposições ao afirmar que o fundamentalismo é da ordem da ritualização da verdade para a rejeição do diálogo, e não se restringe ao campo religioso, existe também na política, por exemplo. Mas a política é o caminho de prevenção contra o fundamentalismo e do combate a ele, pois, se o fundamentalismo é perigoso e violento, é pelo diálogo que pode ser encontrada "a possibilidade de substituir a violência pela comunicação" (GIDDENS, PIERSON, 2000, p. 97). 
Religare, ISSN: 19826605, v.15, n.2, dezembro de 2018, p.354-381.

Na modernidade cosmopolita, não há confiança (muito menos total) sem risco, são categorias, ao mesmo tempo, antagônicas e complementares, e assumem a condição de organização do tempo futuro. "A noção de risco remonta ao início do período moderno e assinala a tentativa de libertar-se do passado para encarar o futuro" (GIDDENS; PIERSON, 2000, p. 77). Viver o presente com abertura ao futuro - relação que exige, cada vez mais, abertura ao diálogo com o outro - é uma das consequências da aceitação do risco, "afinal, uma raiz do termo 'risk' no original português significa 'ousar'" (GIDDENS, 2000, p. 45). Abrir-se para o futuro é arriscar-se, é ousar; a negação disso tudo é a estruturação das explicações e atividades em função dos fatos passados, o que caracteriza a vida daquelas pessoas que "tendem a pensar em termos de destino" (GIDDENS; PIERSON, 2000, p. 78) - ou de eleição com uma missão, para ficar com termos já utilizados, como no caso dos fundamentalistas apóstolos na democracia brasileira.

Como fundamentalismo pode ser muita coisa mesmo, numa fictícia lista inspirada em Borges, depois do etcétera, nossa proposta foi de classificá-lo como "a exclusão do outro na história do mesmo"; como o passo final neste artigo, proponho que pensemos no antagonismo do fundamentalismo - por exemplo, a democracia no campo político - como "a intrusão do outro na história do mesmo". As diferenças que fazem vacilar as certezas e inquietam todas as intransigências precisam agir como intrusas na convivência com a mesmice fundamentalista. Dos fundamentalistas talvez não tiremos nenhum riso, eles preferem ser sisudos, mas importa perturbar seu pensamento e sua ação. Ribeiro (2107) é taxativo ao dizer que o fundamentalismo nunca foi moderno porque não aceita críticas e, principalmente, não elabora autocrítica características da modernidade em sua reflexividade. De dentro do fundamentalismo, portanto, não devemos esperar disposição para aberturas. A classificação da vida, das gentes e das coisas pela inclusão da diferença tem de passar de fora para dentro do fundamentalismo, fazendo-o vacilar. É hora da 
Religare, ISSN: 19826605, v.15, n.2, dezembro de 2018, p.354-381.

intrusão da diferença na história do mesmo. A diversidade, em todas as vertentes, não pode ceder mais nenhum espaço à mesmice.

\section{Referências}

BARROS, Douglas Ferreira. Fundamentalismo religioso no Brasil contemporâneo e a democracia em questão. In: ALMEIDA, Leandro Thomaz de (Org.). Rostos do fundamentalismo: abordagens histórico-críticas. São Paulo: Terceira Via, 2017. p. 109-139.

COX, Harvey. O futuro da fé. São Paulo: Paulus, 2015.

DUFOUR, Dany-Robert. Capitalismo, religião e espetáculo. In: MOREIRA, Alberto da Silva; LEMOS, Carolina Teles; QUADROS, Eduardo Gusmão de (Orgs.). A religião entre o espetáculo e a intimidade. Goiânia: Ed. PUC Goiás, 2014. p. 11-27.

ECO, Umberto. Definições léxicas. In: BARRET-DUCROCQ, Françoise (Dir.). A intolerância. Rio de Janeiro, Bertrand Brasil, 2000. p. 15-19.

FUX, Jacques; GOMES, Luciana Andrade. Os problemas de classificação nas obras de Jorge Luis Borges e Georges Perec. Em tese, Belo Horizonte, v. 19, n. 1, p. 227-246, jan.-abr. 2013. Disponível em: http://www.periodicos.letras.ufmg.br/index.php/emtese/article/viewFile/5137/4 586. Acesso em: 31 ago. 2017.

GIDDENS, Anthony. Mundo em descontrole: o que a globalização está fazendo de nós. Rio de Janeiro: Record, 2000.

GIDDENS, Anthony; PIERSON, Christopher. Conversas com Anthony Giddens: o sentido da modernidade. Rio de Janeiro: Ed. FGV, 2000.

ORO, Ivo Pedro. O outro é o demônio: uma análise sociológica do fundamentalismo. São Paulo: Paulus, 1996.

PIERUCCI, Antônio Flávio. Ciladas da diferença. São Paulo: Ed. 34, 1999.

PIERUCCI, Antônio Flávio. Fundamentalismo e integrismo: os nomes e a coisa. Revista USP, São Paulo, n. 13, p. 144-156, 1992. Disponível em: http://www.revistas.usp.br/revusp/article/view/25620/27360. Acesso em: 31 ago. 2017.

PIERUCCI, Antônio Flávio. Religião como solvente - uma aula. Novos Estudos: CEBRAP, n. 75, p. 111-127, jul. 2006. Disponível em: http://www.scielo.br/scielo.php?script=sci_arttext\&pid=S0101-

33002006000200008. Acesso em: 8 ago. 2018.

RIBEIRO, Osvaldo Luiz. Seis "teses" sobre o fundamentalismo: provocações iniciais. In: ALMEIDA, Leandro Thomaz de (Org.). Rostos do fundamentalismo: abordagens histórico-críticas. São Paulo: Terceira Via, 2017. p. 141-160.

SCHWEITZER, Louis. O fundamentalismo protestante. In: FUNDAMENTALISMOS, integrismos: uma ameaça aos direitos humanos. São Paulo: Paulinas, 2001. p. 31-42. 
Religare, ISSN: 19826605, v.15, n.2, dezembro de 2018, p.354-381.

TODOROV, Tzvetan. A conquista da América: a questão do outro. 2 ed. São Paulo: Martins Fontes, 1999.

VARGAS LLOSA, Mario. A civilização do espetáculo: uma radiografia do nosso tempo e da nossa cultura. Rio de Janeiro: Objetiva, 2013.

WEBER, Max. Rejeições religiosas do mundo e suas direções. In: GERTH, H. H.; MILLS, C. Wright. Max Weber: ensaios de sociologia. 5 ed. Rio de Janeiro: Guanabara Koogan, 1982. p. 371-410.

Recebido em 13-09-2018.

Aprovado em 20-01-2019. 